of soil and not in the open field, it seems safe to conclude that the take-all fungus is likely to disappear more quickly from soil under a non-susceptible crop than from soil kept fallow. This observation may explain the success of a system followed by certain English farmers for continuous barley growing. Barley is susceptible to the take-all disease, and the second or third consecutive barley crop on the same land is sometimes severely attacked. But barley undersown with trefoil (which makes a luxuriant growth in late summer and autumn after the barley has been cut, and is then ploughed in as a preparation for the next barley crop) has not so far been observed to suffer from take-all. To explain this observation, it is suggested that the active growth of the legume after barley harvest keeps the available nitrogen content of the soil at a very low level, with resulting detriment to the longevity of o. graminis, most of which is unable to survive until sowing of the new barley crop in the spring.

Rothamsted Experimental Station, S. D. Garrett.

$$
\text { Harpenden. }
$$

1 Garrett, S. D., Ann. Appl. Biol., 25, 742 (1938).

${ }^{2}$ Garrett, S. D., Ann. Appl. Biol., 27, 199 (1940).

\section{Vacuum Filtration of Sewage Sludge}

Ir is interesting to $\mathrm{know}^{1}$ that the results of experiments on the aeration of sewage sludge, as a preliminary to coagulation and vacuum filtration, may shortly be published by the Rivers Department, Manchester.

In Great Britain, the first experiments on vacuum filtration of activated sludge appear to be those carried out at Sheffield sewage works by the late John Haworth ${ }^{2}$, and mentioned in a paper published by him in 1923. During the discussion on this paper, it was stated that by further aeration of surplus activated sludge in separate tanks, it is possible to bring it into a condition in which a great deal of water can be drawn off and the sludge can be more easily filter-pressed.

It is unfortunate that the results of subsequent experiments at Sheffield, by Howarth and J. $H$. Edmondson (his successor), have not been published. The latter has been working on the subject for the past seven years and, in his early experiments, found that activated sludge is most easily filtered when in a nitrifying condition and within three to six hours after leaving the sewage purification plant. In a tentative scheme which Edmondson has prepared, it is intended to store surplus activated sludge in a bio-aeration plant, designed for the dual purposes of aeration and equalizing the flow, previous to vacuum filtration.

West Riding of Yorkshire Rivers Board,

J. H. GARner.

(Chief Inspector.)

Wakefield.

INATURE, 153, 249 (1943).

2 Haworth, J., Proc. Assoc. of Managers of Sewage Disposal Works (1923).

\section{Nutritional Research in the Crown Colonies}

Prof. C. M. YongE ${ }^{1}$ refers to the need for the establishment of a centre of marine research in the West Indies, and further, he urges the creation of a fisheries' station there, after the War.
In 1941, I wrote to the Lancet, putting forward a similar requirement for nutritional research centres in the Crown Colonies. As yet, they possess no such organizations, as we see, for example, in India (Coonoor) or in China (Henry Lester Institute), to say nothing of the relatively great number of research units in Great Britain. Apart from the very obvious nature and even elementary considerations of such need, the Crown Colonies-with their severe incidence of deficiency disease states out of all parallel to our own country-afford quite exceptional opportunity for sustained nutritional research, as for example, their different dietaries, the different or apparently different factors which lead up to the same expression in types of disease, in different races and peoples. Again we have to remember, also, all nutritional investigation we should undertake in these Colonies primarily affects the welfare of those peoples, not ourselves.

Research institutes not only afford opportunity for research, but they also provide facilities for local training within the country concerned, and they offer security of tenure for the locally trained man. Many Indians, trained at Coonoor, now are not only contributing to the solution of many of their own. food problems, as they should be, but also have become well-known authorities in a much wider field. Little of such opportunity has been given to our Crown Colonies, with the comparatively few exceptions of expensively trained home men, and even so, without the full facilities, there has been little enough opportunity for sustained or inclusive research.

Similar research centres, therefore, are long overdue, not only for the West Indies but also for West Africa, East Africa and so forth.

Hillside Cottage,

Corfe View Road, Parkstone,

Dorset.

Aug. 1.

${ }^{2}$ NATURE, 152, 136 (1943).

\section{James Prescott Joule and the Unit of Energy}

Prof. H. S. Allen's communication in NATURE of September 25 prompts me to mention a recent conversation which $I$ had with a Manchester man whose evidence I should have considered trustworthy. He mentioned that in his youth he had known a man who had been well acquainted with Joule, and that he had told him that Joule himself always pronounced his name 'Jole', with the first vowel as in 'Joe'.

I should be interested to know whether there is any corroboration of this third possible pronunciation. A. W. V. Mace.

Rugby School Science Laboratory, Barby Road, Rugby.

Further to Prof. H. S. Allen's communication in Nature of September 25, I may say that Joule used to live not far from my home at Sale, near Man. chester, and I have often seen his house. His name was pronounced 'Joole', thus confirming Prof. G. W. O. Howe's pronunciation.

30 St. Ann Street,

Graham Renshaw.

Manchester, 2. 